holder, a plan originally recommended by Mareschal, a French army surgeon (vaccinostyle individuel), will be found useful. After vaccinating a patient the pen is thrown away and a fresh one used for the next case.

Upper Gloucester-place, N.W.

\section{A SECOND CASE OF SUCCESSFUL OPERA- TION FOR PERFORATION IN TYPHOID FEVER. ${ }^{1}$}

By ANTHONY A. BOWLBY, C.M.G., F.R.C.S. ENG., LECTURER ON SURGERY AT ST. BARTHOLOMEW'S HOSPITAL.

THe patient was a boy, aged 10 years, who was admitted into St. Bartholomew's Hospital under the care of Dr. Norman Moore on Sept. 1st, 1900. He was in the third day of an attack of typhoid fever and beyond the fact that the case was severe and prolonged it called for no special comment except that after the temperature had come down to normal on the thirteenth day he suffered from a severe relapse on the twenty-first day and had again a very high temperature, reaching $1054^{\circ} \mathrm{F}$. on one occasion. The date of the relapse was Sept. 19th. On Oct. lst the temperature was still above normal $\left(101^{\circ}\right)$ and tympanites, which had been present throughout, was still well marked. There was also some crepitation at the bases of the lungs. On the 2nd, after a slight shivering fit, the patient became blanched and cold, the temperature sinking to $97^{\circ} 6^{\circ}$, but there was no subsequent evidence of hæmorrhage or pain. On the 3rd he seemed to be better but the temperature was still $101^{\circ}$. The abdomen was less distended and the boweis acted without enemata. On the 4th the temperature was normal but the abdomen was again distended. The pulse was $96 \quad$ A little before 3 P. M. he complained of some difficulty in micturition and while passing urine he was seized with severe pain in the abdomen. The temperature half an hour earlier had been $102 \cdot 6^{\circ}$ but after the attack of pain the patient sweated profusely and it dropped to $98^{\circ}$. For the next half hour the boy was screaming with pain and was exceedingly restless. He then became quieter and collapsed, with sunken eyes, a cold sweat, and shivering. The pulse had gone up meantime to 140. I saw him at 4.30 P.M. with Dr. Norman Moore and found his general condition to be as above described. The abdominal wall was hard and fixed during respiration and I agreed with Dr. Norman Moore that perforation had almost certainly taken place and quite concurred in his proposal that an operation should be undertaken at once. At 5 P. M. therefore, two hours after the symptoms of perforation, the abdomen was opened in the middle line and at once free gas was found in the peritoneum. A considerable quantity of almost clear fluid welled up but there was no large collection of fæcal matter. The intestines were so much distended that several coils had to be allowed to extrude and they were kept wrapped in hot towels. Many areas of inflamed peritoneum indicated the affected Pezer's glands. I then sought for the cæcum and after finding it I rapidly passed the small intestine through my hands till I found a perforation situated less than two feet from the ileo-crcal valve. The bowel was not adherent or otherwise altered nor could any induration be felt in its walls, but the peritoneum corresponding to the shape of a Peyer's patch was very red and injected. The opening in the intestine was quite small, being not much larger than a pin's head. I wiped the bowel clean and then closed the opening by five Lembert's sutures of fine silk. The greater part of the incision was now closed and a glass drainage-tube was placed in its lower end. Owing to there being no complications the operation was completed in about 20 minutes and at the end of it the patient's general condition was none the worse for the handling and exposure of the bowel. The peritoneum was not douched but the intestines were carefully wiped clean and all fluid was completely mopped up from the pelvis and elsewhere with sponges. For several days the boy remained very ill and in the early morning after the operation the pulse was still 150 , the temperature being $1004^{\circ}$. There had been no sickness and flatus was passed. The patient 1 A paper read at a meeting of the Clinical society of London on
Dec. 12th, 1902. was fed by nutrient enemata and only a lititle water or ice was given by the mouth. The abdomen remained distended. After this time there was steady and rapid improvement except for some sickness on the 7 th and a troublesome cough, so that by the 10th (six days after the operation) the boy seemed to be convalescent. On that day, however, he had a slight epileptiform attack and in the evening a more severe series of fits, necessitating the administration of chloroform. This threw him back and weakened him but he again rallied and in spite of a return of severe convulsions on the $20 \mathrm{th}$ he ultimately recovered. The tympanitic distension of the abdomen which had been so marked throughout continued till the end of his illness. I saw the boy some months later and found him to be in excellent healtb.

I have already recorded a similar case of operation for perforation of typhoid ulcer in vol. Ixxx. of the 'I'ransactions of the Royal Medical and Chirurgical Society (in conjunction with Sir Lauder Brunton) and in that case also, which had a similar satisfactory ending, the patient was operated upon late in an attack of typhoid fever, for he was in the sixth week of the illness and was at the time suffering from a relapse. In that case there were much induration of the perforated Pezer's patch and some consequent difficulty in suturing the aperture, but in all other respects the cases had much in common except that at the time of the operation the boy whose case I now record was much more ill than was the first patient and that there was greater distension of the abdomen.

The two cases represent the only patients I have operated upon and there can be no doubt that they represent two lives saved. On the other hand, however, I do not regard them as at all typical cases of typhoid perforation but rather as typical of a special class in which perforation occurs after the fever is practically over and in which the general condition of the patient is otherwise relatively good. In such patients as these the symptoms of perforation are generally well marked and the diagnosis is readily arrived at. But in very many other cases the reverse is true, for it not infrequently happens that the perforation occurs when the fever is yet high in patients who are nearly or quite unconscious and in whom there is no perception or expression of pain and who may have distended and tympanitic abdomens before perforation occurs. Many such patients are already at death's door and in not a few of such cases in addition to the perforation there are numerous other areas where the intestine is so rotten that its giving way is only a question of time. It is not to be supposed that even if an ulcerated bowel is sutured many such patients can recover and in some of them at least the operation of suture may be practically impossible. I saw at least one such case in South Africa with Dr. H. H. Tooth in which the patient was quite unconscious and manifestly dying. Dr. Tooth suspected that there might be a perforation but as the symptoms were not clear no operation was undertaken and the same day the man died. A post-mortem examination showed that the intestine was so matted and adherent to the peritoneum and mesentery that even after death it could with difficulty be unravelled and though there was a per-? foration I do not think that it would have been discovered by operation, even if the patient's condition had permitted one to be performed.

As surgeons we are of course entirely dependent on physicians for the opportunity of operating on cases of perforation in typhoid fever and it is evident that it is for us to convince them that operations may save life. The case which I have recorded is one in which the saving of life was primarily due to Dr. Norman Moore and in recording it I do not wish to suggest that all cases are likely to be so successful. On the other hand, $I$ do think that in the present position of intestinal surgery there is good reason to advocate that the chance given by operation should not be withheld in any case of perforation, and I would suggest that in all such cases where perforation is suspected a surgeon should be called in as promptly as possible.

Manchester-square, $\mathrm{W}$.

Weston-super-Mare Isolation Hospital.--On Dec. 17th an additional ward, which has been recently added to the Weston-super-Mare Isolation Hospital, was formally opened by the chairman of the sanitary committee. The new ward will provide accommodation for elght patients and has been erected at a cost of $£ 300$. The hospital now contains 28 beds. 